\title{
Valvular Calcific Deposits and Mortality in Peritoneal Dialysis Patients: A Propensity Score-Matched Cohort Analysis
}

\author{
Aiwen Shen ${ }^{a}$ Linsen Jiang $^{a} \quad$ Yunhuan Tian $^{b} \quad$ Ying Lu $^{\mathrm{a}} \quad$ Zhi Wang $^{\mathrm{a}}$ \\ Huaying Shen $^{\mathrm{a}}$ Kai Song ${ }^{\mathrm{a}}$ Sheng Feng ${ }^{\mathrm{a}}$ \\ aDepartment of Nephrology, Second Affiliated Hospital of Soochow University, Suzhou, China; \\ ${ }^{b}$ Department of Nephrology, East District of Suzhou Municipal Hospital, Suzhou, China
}

\section{Keywords}

Peritoneal dialysis - Cardiovascular risk · Mortality · Cardiac valve calcification - Propensity score

\begin{abstract}
Objective: This study aimed to compare mortality between peritoneal dialysis (PD) patients with and without cardiac valve calcification (CVC). Methods: Patients undergoing PD at the dialysis center of the Second Affiliated Hospital of Soochow University from January 1, 2009, to June 31, 2016, were included and followed through December 31, 2018. The inclusion criteria were (1) age $\geq 18$ years and (2) PD vintage $\geq 1$ month. The exclusion criteria were (1) a history of hemodialysis or renal transplantation before PD; (2) diagnosed congenital heart disease, rheumatic heart disease, or hyperthyroid heart disease; and (3) loss to follow-up. Differences in mortality rates were compared using a Fine-Gray proportional hazards model. Results: A total of 310 patient cases were included in this study, including 237 cases without CVC (non-CVC group). The CVC group included 59 cases with aortic valve calcification (AVC), 6 cases with mitral valve calcification (MVC), and 8 cases of AVC associated with MVC. After propensity score matching, 68 pairs were selected. The
\end{abstract}

karger@karger.com www.karger.com/crm

Karger $\stackrel{\text { ' }}{5}$
(C) 2021 The Author(s)

Published by S. Karger AG, Basel

This is an Open Access article licensed under the Creative Commons Attribution-NonCommercial-4.0 International License (CC BY-NC) (http://www.karger.com/Services/OpenAccessLicense), applicable to the online version of the article only. Usage and distribution for commercial purposes requires written permission. multivariate competing risk regression analysis revealed that age (hazard ratio [HR]: 1.06, 95\% confidence interval [95\% Cl]: 1.03-1.10, $p<0.001$ ) and CVC group (HR: 1.83, 95\% $\mathrm{Cl}: 1.04-3.20, p<0.05)$ were independent risk factors associated with mortality. No significant difference was observed in technique survival between the 2 groups. Conclusion: CVC is an independent risk factor for mortality in PD patients.

(C) 2021 The Author(s)

Published by S. Karger AG, Basel

\section{Introduction}

Chronic kidney disease-mineral bone disorder (CKDMBD) is a systemic disorder characterized by abnormal mineral metabolism, vascular calcification, and abnormal bone formation $[1,2]$. CKD-MBD can increase cardiovascular complications due to left ventricular hypertrophy and arterial calcification $[3,4]$. CKD-MBD is a common complication among peritoneal dialysis (PD) patients, impacting the quality of life and the occurrence and prognosis of other complications experienced by PD

\section{Aiwen Shen and Linsen Jiang contributed equally to this work.}

Correspondence to:

Sheng Feng, fengsheng2@ aliyun.com 
patients [5]. Therefore, the study of cardiac valve calcification (CVC) may reveal strategies for reducing the incidence of PD patients' complications and improve the long-term prognosis of $\mathrm{PD}$ patients.

Current research examining CVC in patients with $\mathrm{CKD}$ is primarily focused on identifying the underlying risk factors. Most of these studies have focused on the effects of nutritional status, inflammatory response $[6,7]$, and dyslipidemia [8] on CVC incidence. Our study has investigated the risk factors associated with new-onset CVC in patients on maintenance PD [9]. Few studies have examined the effects of $\mathrm{CVC}$ on the long-term prognosis of patients with chronic renal disease, and these studies have primarily focused on hemodialysis patients $[10,11]$. However, 1 study explored the relationship between PD and CVC, and the number of samples included in this study was small [12]. A previous study has found that $\mathrm{CVC}$ is associated with presence and severity of coronary artery disease in CKD [13]. But, the mechanism of newonset CVC during PD may be different from that under baseline conditions, and the impacts on prognosis may also be different; however, these aspects have not been explored.

We retrospectively analyzed 310 patients undergoing maintenance PD to study the effects of new-onset CVC on the survival rate among PD patients at baseline and during dialysis. The propensity score matching (PSM) method was used to match the risk factors that may affect PD patients' prognosis, eliminate potential confounding factors, and further explain the relationship between $\mathrm{CVC}$ and $\mathrm{PD}$ patients' prognosis.

\section{Materials and Methods}

\section{Study Subjects}

Four hundred seventy-four patients underwent PD catheter insertion at the Peritoneal Dialysis Center at the Second Affiliated Hospital of Soochow University from January 2009 to June 2016, followed through December 31, 2018. The exclusion criteria included (1) PD treatment for $<3$ months $(n=25)$; (2) echocardiographic examinations not performed during catheterization $(n=$ $123)$; and (3) underlying malignancy $(n=5)$, chronic liver disease, liver cirrhosis $(n=4)$, systemic lupus erythematosus $(n=4)$, rheumatic heart disease $(n=1)$, or congenital heart disease $(n=2)$. A total of 310 patients were eventually included in this study.

\section{Echocardiography}

CVC was defined as bright echoes $>1 \mathrm{~mm}$ on one or more cusps of the aortic valve, mitral valve, or mitral annulus. All included patients underwent echocardiography (Model GE Vivid E9) in the ultrasound room of our hospital. None of the echocardiographic technicians were aware of the patients' detailed clinical conditions.

\section{Data Collection}

Cardiac functional parameters were collected from all enrolled patients at baseline and after 6 months of PD treatment, including the left ventricular end-diastolic diameter (LVEDd), left ventricular end-systolic dimension (LVESD), left ventricular posterior wall thickness at the end of diastole (LVPWT), interventricular septum thickness (IVST), and left ventricular ejection fraction (LVEF). The left ventricular mass (LVM) and left ventricular mass index (LVMI) were calculated by the Devereux formula as follows:

LVM $=1.04 \times\left[\left(\right.\right.$ IVST + LVPWT + LVEDd $^{3}-$ LVEDd $\left.^{3}\right]$ -13.6 ;

BAS $($ body surface area $)=0.0061 \times$ height $+0.0124 \times$ weight

-0.0099 ;

$\mathrm{LVMI}=\mathrm{LVM} / \mathrm{BSA}$.

Left ventricular hypertrophy (LVH) was defined as LVMI >125 $\mathrm{g} / \mathrm{m}^{2}$ in men and LVMI $>120 \mathrm{~g} / \mathrm{m}^{2}$ in women.

\section{Measurement Indices}

Clinical data, including age, gender, BMI, primary disease type, catheterization date, outcome condition, outcome time, history of diabetes, and estimated glomerular filtration rate, were obtained. We collected the first set of fasting biochemical blood indices from all patients during hospitalization for catheterization, including hemoglobin, serum creatinine ( $\mathrm{sCr}$ ), urea nitrogen, albumin, prealbumin (PAB), alkaline phosphatase, parathyroid hormone, serum $\mathrm{Ca}$, serum $\mathrm{P}, \mathrm{C}$-reactive protein (CRP), triglycerides, total cholesterol, high-density lipoprotein, and low-density lipoprotein levels.

\section{Outcome}

All patients were followed up prospectively after the baseline echocardiography measurement. Four patients were lost to followup during the follow-up period, 9 patients were transferred to renal transplantation, 34 patients were transferred to hemodialysis, 6 patients combined PD and hemodialysis, 2 patients recovered renal function, and 86 patients died.

\section{Propensity Score Matching}

Patients in the CVC group were matched with non-CVC group patients using propensity scores. We performed a 1:1 match using 9 covariates, including age, sex, BMI, primary disease type, history of diabetes, serum biochemical, estimated glomerular filtration rate, $\mathrm{LVH}$, and LVEF, as listed in Table 1. In total, 68 patients from the CVC group and 60 patients from the non-CVC group were balanced.

\section{Statistical Analyses}

Statistical analysis was performed using SPSS 22.0 (IBM SPSS, Somers, NY, USA). Data were expressed as the mean \pm SD or the median (interquartile range), depending on the distribution type. Comparisons between 2 groups of data with normal distributions were performed using a $t$ test, whereas comparisons between groups with skewed data were performed using the Mann-Whitney $U$ test, and categorical data were compared with the $\chi^{2}$ test. Differences in event-free survival among groups were examined using the Kaplan-Meier method and compared using the log-rank test. The Cox regression model was used to perform multivariate analysis, both before and after matching, and the risk ratio was calculated. A $p$ value $<0.05$ (2-tailed) was considered significant. 
Table 1. Basic data of CVC and non-CVC groups after PSM

\begin{tabular}{|c|c|c|c|}
\hline Variable & $\begin{array}{l}\text { CVC group } \\
(n=68)\end{array}$ & $\begin{array}{l}\text { Non-CVC group } \\
(n=60)\end{array}$ & $p$ value \\
\hline Gender (male/female) & $42 / 26$ & $37 / 23$ & ns \\
\hline Age, years & $70.1 \pm 10.8$ & $60.3 \pm 15.1$ & 0.003 \\
\hline $\mathrm{BMI}, \mathrm{kg} / \mathrm{m}^{2}$ & $21.9 \pm 3.3$ & $22.6 \pm 2.9$ & ns \\
\hline Duration of dialysis, months & $31.2 \pm 26.9$ & $37.6 \pm 29.0$ & ns \\
\hline Diabetes mellitus (yes/no) & $23 / 45$ & $16 / 44$ & 0.38 \\
\hline LVEF, \% & $62.2 \pm 8.96$ & $59.42 \pm 9.28$ & ns \\
\hline LVH (yes/no) & $51 / 17$ & $49 / 11$ & ns \\
\hline $\mathrm{PTH}, \mathrm{pg} / \mathrm{dL}$ & $204.0(93.8,342.6)$ & $252.2(149.3,424.2)$ & ns \\
\hline $\mathrm{Hb}, \mathrm{g} / \mathrm{L}$ & $110.79 \pm 20.92$ & $105.18 \pm 18.71$ & ns \\
\hline $\mathrm{sCr}, \mu \mathrm{mol} / \mathrm{L}$ & $672.57 \pm 289.89$ & $856.58 \pm 442.11$ & 0.006 \\
\hline BUN, mmol/L & $24.19 \pm 8.52$ & $27.01 \pm 12.75$ & ns \\
\hline $\mathrm{PAB}, \mathrm{g} / \mathrm{L}$ & $0.25 \pm 0.1$ & $0.28 \pm 0.1$ & ns \\
\hline $\mathrm{ALB}, \mathrm{U} / \mathrm{L}$ & $81.87 \pm 30.7$ & $92.12 \pm 38.41$ & ns \\
\hline $\mathrm{sCa}, \mathrm{mmol} / \mathrm{L}$ & $2.06 \pm 0.24$ & $1.95 \pm 0.32$ & 0.019 \\
\hline $\mathrm{sP}, \mathrm{mmol} / \mathrm{L}$ & $1.72 \pm 0.46$ & $1.88 \pm 0.53$ & 0.083 \\
\hline $\mathrm{TC}, \mathrm{mmol} / \mathrm{L}$ & $4.27 \pm 1.13$ & $4.08 \pm 1.0$ & ns \\
\hline $\mathrm{LDL}, \mathrm{mmol} / \mathrm{L}$ & $2.66 \pm 1.0$ & $2.55 \pm 0.75$ & ns \\
\hline $\mathrm{HDL}, \mathrm{mmol} / \mathrm{L}$ & $1.09 \pm 0.37$ & $1.03 \pm 0.32$ & ns \\
\hline $\mathrm{TG}, \mathrm{mmol} / \mathrm{L}$ & $1.46 \pm 0.77$ & $1.42 \pm 0.98$ & ns \\
\hline $\mathrm{ALB}, \mathrm{g} / \mathrm{L}$ & $31.64 \pm 5.38$ & $32.5 \pm 4.97$ & ns \\
\hline $\mathrm{CRP}, \mathrm{mg} / \mathrm{L}$ & $7.95(5.6,23.7)$ & $6.0(5.0,8.6)$ & 0.008 \\
\hline $\mathrm{KT} / \mathrm{V}$ & $1.83 \pm 0.42$ & $1.85 \pm 0.48$ & ns \\
\hline $\mathrm{eGFR}, \mathrm{mL} / \mathrm{min}$ & $6.45 \pm 3.66$ & $6.34 \pm 4.07$ & ns \\
\hline Valve calcification & 68 & - & \\
\hline AVC & 57 & - & \\
\hline MVC & 5 & - & \\
\hline $\mathrm{AVC}$ and $\mathrm{MVC}$ & 6 & - & \\
\hline
\end{tabular}

PSM, propensity score matching; AVC, aortic valve calcification; MVC, mitral valve calcification; CVC, cardiac valve calcification; LVEF, left ventricular ejection fraction; LVH, left ventricular hypertrophy; PTH, parathyroid hormone; sCr, serum creatinine; ALB, albumin; PAB, prealbumin; CRP, C-reactive protein; TG, triglycerides; eGFR, estimated glomerular filtration rate.

\section{Results}

\section{Clinical Data}

Table 2 shows the baseline clinical and demographic characteristics of the entire study population and both groups. In total, 310 patients were included, including 179 men and 131 women, with an average age of $57 \pm 15.9$ years. The primary causes of chronic renal failure included chronic glomerulonephritis in 181 patients, hypertensive nephrosclerosis in 41 patients, diabetic nephropathy in 45 patients, and obstructive uropathy, polycystic kidney disease, or unknown conditions in 43 patients. CVC was observed in 73 (23.5\%) patients: 59 had aortic valve calcification only, 6 had mitral valve calcification only, and 8 had calcification in both valves. Compared with the non-CVC group, the CVC group was older $(p<0.001)$, with a shorter dialysis duration, and featured a higher proportion of patients with diabetes $(p=0.005)$, a higher rate of secondary kidney disease (hypertensive nephropathy, $p=0.012$; diabetic nephropathy, $p=0.015)$, lower $\mathrm{sCr}$ levels $(p=0.002)$, lower PAB levels $(p=0.007)$, and higher CRP levels $(p<0.001)$. No significant differences were found between the 2 groups for any of the other variables examined.

\section{CVC Is an Independent Risk Factor for Mortality}

During the mean follow-up of $40.2 \pm 25.5$ months, 86 patients died. The CVC group's mortality rate was $50.7 \%$, compared with $20.7 \%$ in the non-CVC group. The overall 1 -, 3-, and 5-year survival rates were $86.15,64.9$, and $50 \%$ for patients with CVC, respectively, compared with 97.25 , 91.2 , and $87.75 \%$ in the non-CVC group. According to 
Table 2. Comparison of baseline demographics in CVC and non-CVC groups

\begin{tabular}{|c|c|c|c|c|}
\hline Variable & $\begin{array}{l}\text { Total } \\
(n=310)\end{array}$ & $\begin{array}{l}\text { CVC group } \\
(n=73)\end{array}$ & $\begin{array}{l}\text { Non-CVC group } \\
(n=237)\end{array}$ & $p$ value $^{\mathrm{a}}$ \\
\hline Gender (male/female) & $179 / 131$ & $43 / 30$ & $136 / 101$ & ns \\
\hline Age, years & $57 \pm 15.9$ & $71.2 \pm 10.34$ & $52.4 \pm 14.7$ & $<0.001$ \\
\hline $\mathrm{BMI}, \mathrm{kg} / \mathrm{m}^{2}$ & $22.3 \pm 3.2$ & $21.8 \pm 3.3$ & $22.5 \pm 3.1$ & ns \\
\hline Duration of dialysis, months & $40.2 \pm 25.5$ & $34.9 \pm 27.4$ & $41.89 \pm 24.8$ & 0.042 \\
\hline Diabetes mellitus (yes/no) & $69 / 241$ & $25 / 48$ & $44 / 193$ & 0.005 \\
\hline Primary disease type & & & & 0.007 \\
\hline Chronic nephritis, $n(\%)$ & $181(58.4)$ & $31(42.5)$ & $150(63.3)$ & 0.002 \\
\hline Hypertensive nephropathy, $n(\%)$ & $41(13.2)$ & $16(21.9)$ & $25(9.1)$ & 0.012 \\
\hline Diabetic nephropathy, $n(\%)$ & $45(14.5)$ & $17(23.3)$ & $28(11.8)$ & 0.015 \\
\hline Others, $n(\%)$ & $43(13.9)$ & $9(12.3)$ & $34(14.3)$ & ns \\
\hline LVEF, \% & $61.04 \pm 8.24$ & $61.85 \pm 9.11$ & $60.77 \pm 7.97$ & ns \\
\hline LVH (yes/no) & $219 / 91$ & $54 / 19$ & $165 / 72$ & ns \\
\hline PTH, pg/dL & $204.9(98.3,387.9)$ & $204.0(91.4,333.9)$ & $207.0(100,416)$ & ns \\
\hline $\mathrm{Hb}, \mathrm{g} / \mathrm{L}$ & $105.96 \pm 19.7$ & $109.94 \pm 20.98$ & $104.89 \pm 19.31$ & ns \\
\hline $\mathrm{sCr}, \mu \mathrm{mol} / \mathrm{L}$ & $784.06 \pm 364.01$ & $670.02 \pm 288.25$ & $819.2 \pm 377.85$ & 0.002 \\
\hline BUN, mmol/L & $24.9 \pm 10.97$ & $23.90 \pm 8.49$ & $25.21 \pm 11.62$ & ns \\
\hline $\mathrm{PAB}, \mathrm{g} / \mathrm{L}$ & $0.28 \pm 0.11$ & $0.25 \pm 0.09$ & $0.29 \pm 0.11$ & 0.007 \\
\hline $\mathrm{ALB}, \mathrm{U} / \mathrm{L}$ & $92.2 \pm 71.55$ & $89.00 \pm 53.94$ & $93.2 \pm 76.23$ & ns \\
\hline $\mathrm{sP}, \mathrm{mmol} / \mathrm{L}$ & $1.98 \pm 0.27$ & $2.07 \pm 0.24$ & $1.95 \pm 0.27$ & 0.17 \\
\hline $\mathrm{sCa}, \mathrm{mmol} / \mathrm{L}$ & $1.78 \pm 0.58$ & $1.70 \pm 0.47$ & $1.81 \pm 0.61$ & ns \\
\hline $\mathrm{TC}, \mathrm{mmol} / \mathrm{L}$ & $4.3 \pm 1.34$ & $4.23 \pm 1.12$ & $4.32 \pm 1.40$ & ns \\
\hline $\mathrm{LDL}, \mathrm{mmol} / \mathrm{L}$ & $2.63 \pm 0.95$ & $2.59 \pm 1.00$ & $2.64 \pm 0.94$ & ns \\
\hline $\mathrm{HDL}, \mathrm{mmol} / \mathrm{L}$ & $1.08 \pm 0.38$ & $1.08 \pm 0.36$ & $1.08 \pm 0.39$ & ns \\
\hline $\mathrm{TG}, \mathrm{mmol} / \mathrm{L}$ & $1.59 \pm 1.06$ & $1.48 \pm 0.78$ & $1.63 \pm 1.14$ & ns \\
\hline $\mathrm{ALB}, \mathrm{g} / \mathrm{L}$ & $31.98 \pm 5.81$ & $31.44 \pm 5.38$ & $32.16 \pm 5.94$ & ns \\
\hline $\mathrm{CRP}, \mathrm{mg} / \mathrm{L}$ & $6.0(5,8.05)$ & $8.0(5.8,23.8)$ & $5.7(5,7.3)$ & $<0.001$ \\
\hline $\mathrm{KT} / \mathrm{V}$ & $1.85 \pm 0.47$ & $1.83 \pm 0.43$ & $1.86 \pm 0.53$ & ns \\
\hline eGFR, $\mathrm{mL} / \mathrm{min}$ & $6.86 \pm 6.25$ & $6.57 \pm 3.66$ & $6.11 \pm 6.89$ & ns \\
\hline
\end{tabular}

CVC, cardiac valve calcification; LVEF, left ventricular ejection fraction; LVH, left ventricular hypertrophy; $\mathrm{PTH}$, parathyroid hormone; sCr, serum creatinine; $\mathrm{ALB}$, albumin; $\mathrm{PAB}$, prealbumin; $\mathrm{CRP}, \mathrm{C}$-reactive protein; TG, triglycerides; eGFR, estimated glomerular filtration rate. ${ }^{a} \mathrm{CVC}$ versus non-CVC.

Table 3. Multivariate Cox regression results after PSM

\begin{tabular}{llcl}
\hline Variable & Hazard ratio & $p$ value & $95 \% \mathrm{CI}$ \\
\hline Age & 1.069 & $<0.001$ & $1.034-1.105$ \\
CVC & 1.832 & 0.034 & $1.048-3.205$ \\
sP & 1.049 & 0.858 & $0.622-1.768$ \\
ALB & 1.010 & 0.699 & $0.962-1.06$ \\
eGFR & 1.068 & 0.075 & $0.993-1.149$ \\
Diabetes mellitus & 1.273 & 0.397 & $0.728-2.227$ \\
LVEF & 0.991 & 0.585 & $0.959-1.024$ \\
\hline
\end{tabular}

PSM, propensity score matching; CVC, cardiac valve calcification; LVEF, left ventricular ejection fraction; ALB, albumin; eGFR, estimated glomerular filtration rate.
CVC Is an Independent Risk Factor for Mortality in PD the Kaplan-Meier analysis, the differences in the survival rates between these 2 groups were significantly different ( $p<0.001$; Fig. 1). No significant difference in technique survival was observed between the 2 groups $(p=0.419$; Fig. 2).

After matching all covariates in the baseline state using the PSM method, 128 patients, including 79 men and 49 women, were finally included in the second sample. Of these, 68 had CVC at baseline. Table 1 shows the baseline clinical and demographic characteristics of both groups after PSM. Compared with the unmatched baseline data in Table 2, there were no significant differences in dialysis time, diabetes mellitus, and PAB between the CVC and non-CVC groups after matching, but the differences in age, $\mathrm{sCr}$, and CRP between the 2 groups were significantly reduced. 


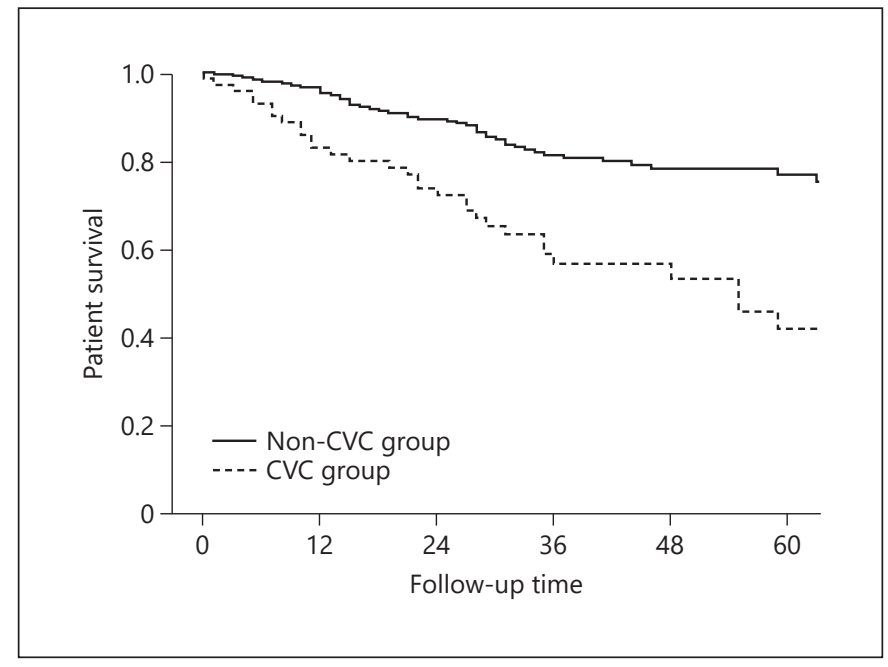

Fig. 1. Kaplan-Meier analysis showing the survival rates between the CVC and non-CVC groups $(p<0.001)$. CVC, cardiac valve calcification.

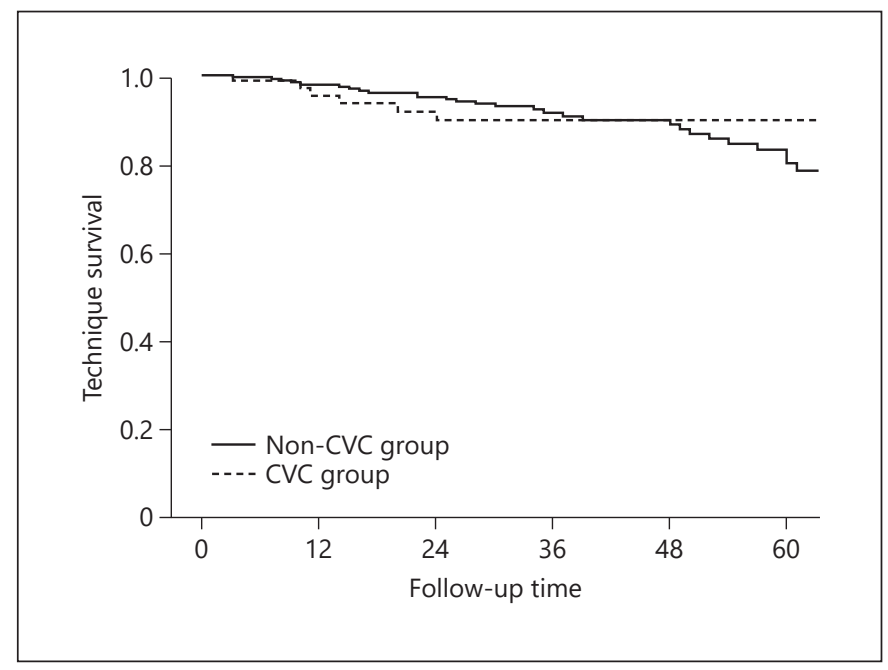

Fig. 2. Comparison of technique survival between the $\mathrm{CVC}$ and non-CVC groups $(p=0.419)$. CVC, cardiac valve calcification.

The Kaplan-Meier analysis was applied to the 128 PSM patients, which showed that the 1-, 3-, and 5-year cumulative survival rates of the non-CVC group were 89.4, 66.4, and $33.5 \%$, respectively, compared with $85.1,64.4$, and $26.4 \%$ for the CVC group. The cumulative survival rates were significantly different between the 2 groups ( $p=0.007$; Fig. 3 ), although the differences in the survival rate between the 2 groups were smaller than before matching was performed. After multivariate Cox regression analysis, adjusted for age, calcium, serum phosphorus, albu-

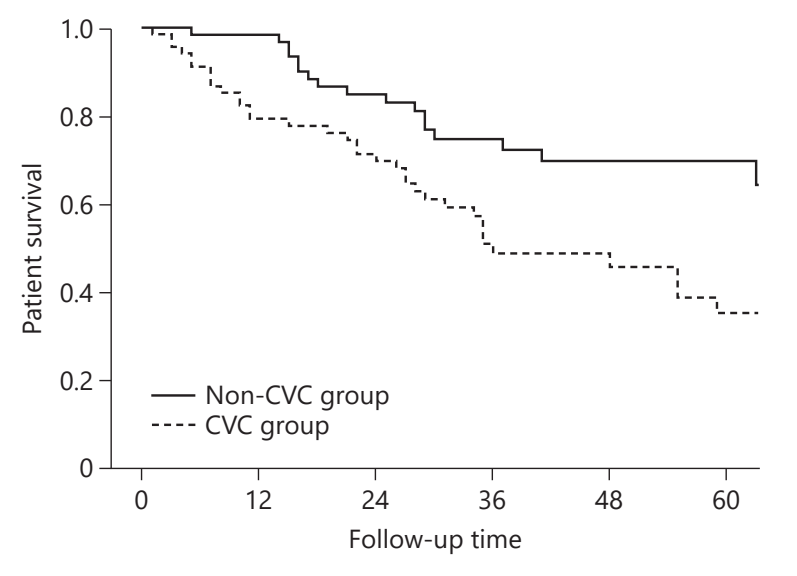

Fig. 3. Kaplan-Meier analysis showing the cumulative survival rates between the CVC and non-CVC groups after PSM ( $p=$ 0.007). PSM, propensity score matching.

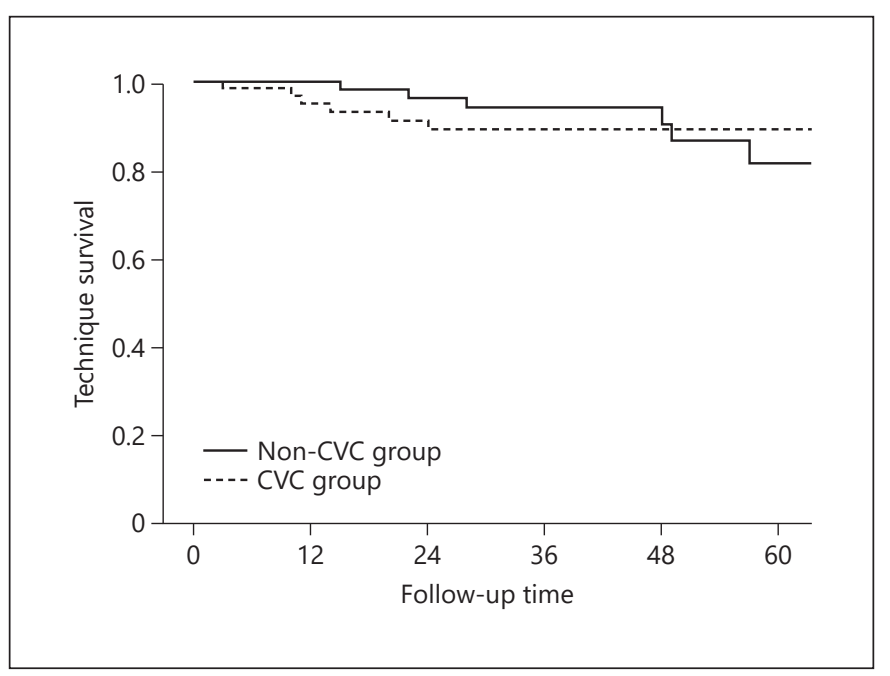

Fig. 4. Comparison of technique survival between the CVC and non-CVC groups after PSM $(p=0.776)$. PSM, propensity score matching; CVC, cardiac valve calcification.

min, CRP, residual renal function, LVEF, diabetes, and other factors, the results showed that CVC $(p=0.034$, $\mathrm{HR}=1.832$; 95\% CI: $1.048-3.205)$ was predictive of allcause survival among PD patients (Table 3 ). No significant difference in technique survival was observed between the CVC and non-CVC groups after PSM ( $p=0.776$; Fig. 4 )

\section{Prognosis of New-Onset CVC during Dialysis}

To evaluate the effect of new-onset CVC on prognosis in $\mathrm{PD}$, patients were divided into the without CVC group 




Fig. 5. Survival of patients without baseline CVC, according to whether they developed new CVC $(p=0.015)$. CVC, cardiac valve calcification.

and the with CVC group at baseline. Based on the delamination standard of new CVC during dialysis, the relationship between valve calcification and the long-term prognosis of PD patients was studied. A total of 68 patients developed CVC $>6$ months after PD onset. The Kaplan-Meier analysis results showed that among patients without CVC at baseline, the prognosis of patients with new-onset CVC during dialysis was worse than that of patients without new-onset CVC (Fig. 5; $p=0.015$ ). Compared with patients with CVC at baseline, those who developed CVC during dialysis had a better prognosis (Fig. 6; $p=0.01$ ).

\section{Discussion}

In this retrospective cohort study, we investigated and compared the mortality among PD patients with and without CVC. We demonstrated that CVC is an independent risk factor for mortality in PD patients. This study was conducted in the real world. The usage of PSM methods was a merit of this study and may underline the results mentioned above.

Consistent with previous studies [14, 15], the KaplanMeier test showed that patient survival was significantly lower in the CVC group than in the non-CVC group. The PSM method was applied to reduce potential confounding factors. We matched age, sex, diabetes, primary disease, $\mathrm{PAB}, \mathrm{sCr}$, urea nitrogen, $\mathrm{CRP}$, and dialysis duration between the CVC and non-CVC groups. After PSM, the

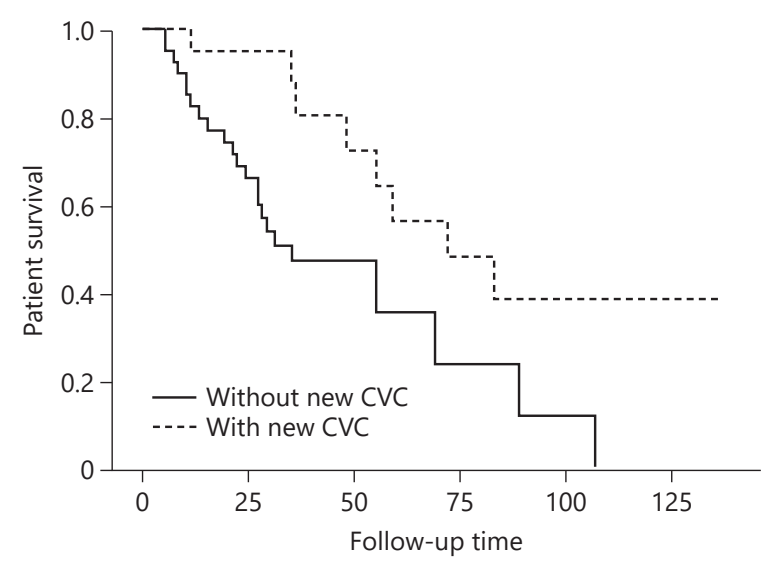

Fig. 6. Survival of patients with baseline CVC according to whether they developed new CVC $(p=0.01)$. CVC, cardiac valve calcification.

Kaplan-Meier analysis and multivariate Cox regression analysis showed that CVC was an independent risk factor for PD mortality. Therefore, we believe that CVC has an effect on all-cause mortality in patients undergoing maintenance PD. This conclusion corresponds with the results of previous studies examining both $\mathrm{PD}$ and hemodialysis [16].

Some related studies have shown that the risk factors associated with valve calcification and atherosclerotic calcification may be similar [17], but the pathogenesis of vascular and valve calcification among dialysis patients differs from that in other populations. Calcification in patients with CKD is characterized by mineral deposition in the intima of blood vessels $[18,19]$, whereas calcification in patients with the nonrenal disease is characterized by atherosclerotic plaques [20]. Therefore, CVC in PD patients at baseline is associated with glucose and lipid metabolism disorders related to complications such as diabetes, hypertension, and hyperlipidemia [5]. In contrast, new-onset CVC formation during dialysis is caused by calcium and phosphorus metabolism disorders, malnutrition, and inflammation.

Heart valve dysfunction in hemodialysis patients is mainly due to systemic calcification and uremic environment. Meanwhile, previous studies showed that elevated phosphate levels are associated with valve calcification [21]. Higher blood phosphorus concentration is associated with vascular and valve calcification [22]. Although this study has not found a relationship between serum calcium or phosphorus level and CVC, serum calcium in 
the CVC group was higher than the non-CVC group after PSM. Thus, the traditional view of the correlation between valvular calcification and the severity of atherosclerosis [23] and coronary artery disease [24] may not be suitable for the study of dialysis.

Because the underlying mechanism associated with calcification at baseline differs from the mechanism underlying the formation of new valve calcification during dialysis, their prognosis effects may differ. Therefore, we conducted a stratified study to determine the occurrence of new CVC during dialysis. The results showed that in patients without valve calcification at baseline, patient cumulative survival rate with new-onset CVC during dialysis was significantly lower than that of patients without new valve calcification. Matthew et al.'s [25] study also showed that the risk of all-cause death in the progressive coronary artery calcification group was 3 times higher than that in the nonprogressive group among patients with non-CKD.

CVC is a hallmark of patients with CKD and end-stage renal disease. The presence and quantity of CVC are driving forces for increased incidence rate and mortality in CKD [26]. CVC is a pathobiological process that actively leads to calcium deposition, including aging, inflammation, CKD, and diabetes [27]. Conventional risk factors for CVC are also risk factors for all-cause and cardiovascular mortality, including age, hypertension, and diabetes. In our study, the combined hypertension and diabetes rates are higher in the CVC group than in the non-CVC group. These results suggest that reasonable control of blood pressure and glucose can delay the progress of CVC.

Compared with conventional factors, unconventional risk factors also play an essential role in CVC, including calcium and phosphorus metabolism, malnutrition, and inflammation [28]. Meanwhile, these factors are also risk factors for worse outcomes in dialysis patients. The CRP was higher in the CVC group because several studies have shown that CVC is associated with various inflammatory proteins, including CRP [29]. CRP is a marker of vascular wall inflammation, and elevated CRP may increase the risk of valve calcification for mortality [30]. CRP reflects systemic inflammation and predicts cardiovascular risk, so dialysis patients need to monitor inflammatory markers [31] regularly.

Furthermore, CVC and paralleled complications can predict a worse outcome. CVC and coronary artery disease are frequently combined both in nondialysis and dialysis patients, which is a reason for total and cardiac death [32-34]. Besides, CVC is related to left ventricular hypertrophy, another proved risk factor for poor outcome in dialysis patients [35]. In total, conventional and unconventional risk factors for CVC and its paralleled complications contribute to a worse prognosis in $\mathrm{PD}$ patients.

Another impressive result is that the cumulative survival rate of patients who developed CVC during dialysis due to new valve calcification increased. This abnormal result may be explained as follows: first, new-onset CVC does not fully represent the progressive calcification, and the calcification of some other valves may become aggravated during dialysis, which is not detectable among our parameters. Second, the average follow-up time was $51 \pm 33$ months in the group with new valve calcification during dialysis, compared with $30 \pm 21$ months in the group without new valve calcification during dialysis, which was a significant difference $(p<$ 0.003 ). The calcification group patients were older and had more complications, which may also contribute to this abnormal result.

One limitation of this study was that nearly $7 \%$ of the patients with basal calcification could not be matched during PSM. Due to this study's retrospective nature, the measurement bias of ultrasound cardiograms cannot be avoided by different persons. Meanwhile, lack of data on intimal calcification and coronary artery disease is another shortage of this study. A randomized prospective multicentered study should be conducted to test the findings in this study.

\section{Acknowledgment}

This study was funded by the Department of Nephrology and Cardiology of the Second Affiliated Hospital of Soochow University. We thank the staff on the Peritoneal Dialysis Center and the Echocardiography Room of the Second Affiliated Hospital of Soochow University for helping with data collection.

\section{Statement of Ethics}

Our study was approved by the Ethics Committee of the Second Affiliated Hospital of Soochow University.

\section{Conflict of Interest Statement}

The authors have no conflicts of interest to declare. 


\section{Funding Sources}

This study was supported by Basic Guidance Project for the Application of Science and Technology for People's Livelihood in Suzhou (Y.L.) (SYS2019071).

\section{Author Contributions}

S.F., H.S., and K.S. designed and conducted the research. A.S. and Y.T. wrote the manuscript. L.J., Y.L., and Z.W. analyzed the data. All authors read and approved the final manuscript.

\section{References}

1 Chen NX, Srinivasan S, O’Neill K, Nickolas TL. Effect of advanced glycation end-products (AGE) lowering drug ALT-711 on biochemical, vascular, and bone parameters in a rat model of CKD-MBD. J Bone Miner Res. 2020; 35(3):608-17.

2 Cianciolo G, La Manna G, Capelli I, Gasperoni L, Galassi A, Ciceri P, et al. The role of activin: the other side of chronic kidney disease-mineral bone disorder? Nephrol Dial Transplant. 2020.

3 Chen NX, Moe SM. Pathophysiology of vascular calcification. Curr Osteoporos Rep. 2015; 13(6):372-80.

4 Viegas C, Araújo N, Marreiros C, Simes D. The interplay between mineral metabolism, vascular calcification and inflammation in chronic kidney disease (CKD): challenging old concepts with new facts. Aging. 2019;11(12):427499.

5 Jegatheesan D, Cho Y, Johnson DW. Clinical studies of interventions to mitigate cardiovascular risk in peritoneal dialysis patients. Semin Nephrol. 2018;38(3):277-90.

6 Dai L, Plunde O, Qureshi AR, Lindholm B, Brismar TB, Schurgers LJ, et al. Aortic valve calcium associates with all-cause mortality independent of coronary artery calcium and inflammation in patients with end-stage renal disease. J Clin Med. 2020;9(2):607.

7 Takahashi H, Ishii H, Aoyama T, Kamoi D, Kasuga $\mathrm{H}$, Ito $\mathrm{Y}$, et al. Association of cardiac valvular calcifications and C-reactive protein with cardiovascular mortality in incident hemodialysis patients: a Japanese cohort study. Am J Kidney Dis. 2013;61(2):254-61.

8 Huang JW, Lien YC, Yang CY, Liu KL, Wu CF, Yen CJ, et al. Osteoprotegerin, inflammation and dyslipidemia are associated with abdominal aortic calcification in non-diabetic patients on peritoneal dialysis. Nutr Metab Cardiovasc Dis. 2014;24(3):236-42

9 Tian Y, Feng S, Zhan Z, Lu Y, Wang Y, Jiang S, et al. Risk factors for new-onset cardiac valve calcification in patients on maintenance peritoneal dialysis. Cardiorenal Med. 2016;6(2): $150-8$.

10 Ureña-Torres P, D’Marco L, Raggi P, GarcíaMoll X, Brandenburg V, Mazzaferro S, et al. Valvular heart disease and calcification in CKD: more common than appreciated. Nephrol Dial Transplant. 2020;35(12):204653.

11 Kitamura K, Fujii H, Nakai K, Kono K, Goto S Nishii T, et al. Relationship between cardiac calcification and left ventricular hypertrophy in patients with chronic kidney disease at hemodialysis initiation. Heart Vessels. 2017; 32(9):1109-16.
12 Wang AY, Wang M, Woo J, Lam CW, Li PK, Lui SF, et al. Cardiac valve calcification as an important predictor for all-cause mortality and cardiovascular mortality in long-term peritoneal dialysis patients: a prospective study. J Am Soc Nephrol. 2003;14(1):159-68.

13 Kim IY, Kim MJ, Lee DW, Lee SB, Shin MJ, Rhee $\mathrm{H}$, et al. Cardiac valve calcification is associated with presence and severity of coronary artery disease in patients with pre-dialysis chronic kidney disease. Clin Exp Nephrol. 2015;19(6):1090-7.

14 Raggi P, Bellasi A, Gamboa C, Ferramosca E, Ratti C, Block GA, et al. All-cause mortality in hemodialysis patients with heart valve calcification. Clin J Am Soc Nephrol. 2011;6(8):1990-5.

15 Younis D, Bahie A, Elzehery R, El-Kannishy G, Wahab AM. Association between serum dickkopf-1 (DKK-1) glycoprotein and calcific deposits on cardiac valves and carotid intimalmedial thickness in hemodialysis patients. Cardiorenal Med. 2020;10(5):313-22.

16 Wang Z, Jiang A. Cardiac valve calcification and risk of cardiovascular or all-cause mortality in dialysis patients: a meta-analysis. BMC Cardiovasc Disord. 2018;18(1):12.

17 Chen HY, Engert JC, Thanassoulis G. Risk factors for valvular calcification. Curr Opin Endocrinol Diabetes Obes. 2019;26(2):96-102.

18 Crouthamel MH, Lau WL, Leaf EM, Chavkin NW, Wallingford MC, Peterson DF, et al. Sodium-dependent phosphate cotransporters and phosphate-induced calcification of vascular smooth muscle cells: redundant roles for PiT-1 and PiT-2. Arterioscler Thromb Vasc Biol. 2013;33(11):2625-32.

19 Sikura K, Potor L, Szerafin T, Oros M, Nagy P. Hydrogen sulfide inhibits calcification of heart valves; implications for calcific aortic valve disease. Br J Pharmacol. 2020;177(4):793-809.

20 Youssef A, Clark JR, Koschinsky ML, Boffa MB. Lipoprotein(a): expanding our knowledge of aortic valve narrowing. Trends Cardiovas Med. 2020.

21 Rubel JR, Milford EL. The relationship between serum calcium and phosphate levels and cardiac valvular procedures in the hemodialysis population. Am J Kidney Dis. 2003;41(2): 411-21.

22 Adeney KL, Siscovick DS, Ix JH, Seliger SL, Shlipak MG, Jenny NS, et al. Association of serum phosphate with vascular and valvular calcification in moderate CKD. J Am Soc Nephrol. 2009;20(2):381-7.

23 Adler Y, Levinger U, Koren A, Gabbay R, Shapira Y, Vaturi M, et al. Association between mitral annulus calcification and peripheral arterial atherosclerotic disease. Angiology. 2000; 51(8):639-46.
24 Kim IY, Kim MJ, Lee DW, Lee SB, Shin MJ, $\mathrm{Rhee} \mathrm{H}$, et al. Cardiac valve calcification is associated with presence and severity of coronary artery disease in patients with pre-dialysis chronic kidney disease. Clin Exp Nephrol. 2015;19(6):1090-7.

25 Budoff MJ, Hokanson JE, Nasir K, Shaw LJ, Kinney GL, Chow D, et al. Progression of coronary artery calcium predicts all-cause mortality. JACC Cardiovasc Imaging. 2010;3(12) 1229-36.

26 Brandenburg VM, Schuh A, Kramann R. Valvular calcification in chronic kidney disease. Adv Chronic Kidney Dis. 2019;26(6):464-71.

27 Wang Z, Jiang A, Wei F, Chen H. Cardiac valve calcification and risk of cardiovascular or allcause mortality in dialysis patients: a metaanalysis. BMC Cardiovasc Disord. 2018;18(1): 12.

28 Wang C, Jiang L, Feng S, Shi Y, Shen H, Shi X, et al. Risk factor analysis of calcification in aortic and mitral valves in maintenance peritoneal dialysis patients. Kidney Blood Press Res. 2013;37(4-5):488-95.

29 Wang AY, Woo J, Wang M, Sea MMM, Ip R, Li PKT, et al. Association of inflammation and malnutrition with cardiac valve calcification in continuous ambulatory peritoneal dialysis $\mathrm{pa}$ tients. J Am Soc Nephrol. 2001;12(9):1927-36.

30 Takahashi H, Ishii H, Aoyama T, Kamoi D, Kasuga $\mathrm{H}$, Ito $\mathrm{Y}$, et al. Association of cardiac valvular calcifications and C-reactive protein with cardiovascular mortality in incident hemodialysis patients: a Japanese cohort study. Am J Kidney Dis. 2013;61(2):254-61.

31 Carrero JJ, Stenvinkel P. Persistent inflammation as a catalyst for other risk factors in chronic kidney disease: a hypothesis proposal. Clin J Am Soc Nephrol. 2009;4(Suppl 1):S49-55.

32 Qian J, Chen Z, Ge J, Ma J, Chang S, Fan B, et al. Relationship between aortic valve calcification and the severity of coronary atherosclerotic disease. J Heart Valve Dis. 2010;19(4): 466-70.

33 Bellasi A, Ferramosca E, Ratti C, Block G, Raggi P. Cardiac valve calcification is a marker of vascular disease in prevalent hemodialysis patients. J Nephrol. 2012;25(2):211-8.

34 Goodman WG, Goldin J, Kuizon BD, Yoon C, Gales B, Sider D, et al. Coronary-artery calcification in young adults with end-stage renal disease who are undergoing dialysis. N Engl J Med. 2000;342(20): 1478-83.

35 Ventura JE, Tavella N, Romero C, Petraglia A, Báez A, Muñoz L. Aortic valve calcification is an independent factor of left ventricular hypertrophy in patients on maintenance haemodialysis. Nephrol Dial Transplant. 2002;17(10): 1795-801. 